\title{
Evaluating patient preference and satisfaction for human immunodeficiency virus therapy in France
}

\author{
This article was published in the following Dove Press journal: \\ Patient Preference and Adherence \\ 10 July 2017 \\ Number of times this article has been viewed
}

\section{Sylvie Brégigeon-Ronot,' Antoine Cheret, ${ }^{2,3}$ André Cabié, ${ }^{4}$ Thierry Prazuck, ${ }^{5}$ Alain Volny-Anne, ${ }^{6}$ Shehzad Ali, ${ }^{7}$ Catherine Bottomley, ${ }^{7}$ Laurent Finkielsztejn, ${ }^{8}$ Caroline Philippe, ${ }^{9}$ Jean- Jacques Parienti ${ }^{10-12}$}

'Clinical Immunohematology Department, Marseille Public University Hospital System (AP-HM), Sainte-Marguerite Hospital, Aix-Marseille University, Marseille, ${ }^{2}$ Department of Infectious Diseases, GuyChatilliez Hospital, Tourcoing, ${ }^{3}$ Internal Medicine Department, Paris Public University Hospital System (AP-HP), Bicêtre University Hospital Center, EA 7327, University Paris Descartes, Paris, ${ }^{4}$ Infectious and Tropical Diseases Department, French National Institute of Health and Medical Research (INSERM), CIC I424, Martinique University Hospital Center, Fort De France, Martinique, ${ }^{5}$ Infectious Diseases Department, Orleans Regional Hospital Center, Orléans, ${ }^{6}$ Patient, Paris, France; ${ }^{7} \mathrm{CON}$, Contract Research Organization, Patient Reported Outcomes Department, Oxford, United Kingdom; ${ }^{8} \mathrm{ViiV}$ Healthcare, Medical affairs, Marly le Roi, ${ }^{9} Q u a l e e s$, Contract Research Organization, Epidemilogy Department, Paris, ${ }^{10}$ Infectious Diseases Department, Caen University Hospital Center, "Biostatistics and Clinical Research Unit, Caen University Hospital Center, ${ }^{12}$ EA2656 Microbial Adaptation Research Group (GRAM 2.0), Caen Normandy University, Caen, France

Correspondence: Jean-Jacques Parienti Maladies Infectieuses, $\mathrm{CHU}$ de Caen, Avenue de la Côte de Nacre, 14003 Caen, France

Tel +3323। 065774

$\mathrm{Fax}+33231065860$

Email parienti-jj@chu-caen.fr
Objectives: The objectives were 1) to elicit relative preferences for attributes of antiretroviral therapies (ART) in people living with HIV (PLWH) and 2) to explore satisfaction and adherence with current ART.

Patients and methods: We conducted a multicenter cross-sectional study, consecutively enrolling PLWH receiving an ART. The quantitative part estimated the strength of preference for different attributes using an online discrete choice experiment (DCE). DCE data were analyzed using a mixed logit regression model. Qualitative data were collected through individual interviews. A preliminary coding framework was developed which was then further refined and applied during thematic analysis of factors influencing satisfaction and adherence.

Results: A total of 101 PLWH took part in the quantitative part and 31 in the qualitative part. Over $90 \%$ had an undetectable viral load. Quantitative data revealed a strong preference for a treatment with limited drug-drug interactions, diarrhea and long-term health problems $(P<0.0001)$, and that did not need to be taken on an empty stomach $(P<0.0001)$. Patients also preferred to avoid problems associated with treatment failure $(P<0.0001)$ or one that left them with a higher viral load after the first weeks of treatment $(P=0.044)$. Differences in CD4 cell count, and pills that must be taken with food were not significant drivers of treatment choice. The strength of these attributes was reflected in the qualitative data, highlighting the importance patients place on treatment efficacy, and also suggesting that some of these attributes may impact adherence. Many factors influencing adherence and satisfaction with treatment were identified, including pill size, worry about sexual transmission and impact on social life.

Conclusion: Most of the attributes included in this survey were important to participants when choosing an ART, in particular those related to quality of life, and these should be taken into account in order to optimize adherence and satisfaction.

Keywords: antiretroviral therapy, adherence, HIV infection, preference elicitation, satisfaction, ARV treatments

\section{Introduction}

The treatment of human immunodeficiency virus (HIV) infection using current antiretroviral drugs (ARVs) is more effective, better tolerated and simpler to administer than regimens used in the past. ${ }^{1}$ This therapeutic advance has contributed to a dramatic reduction in HIV-associated morbidity and mortality in people living with HIV (PLWH), and has changed HIV into a chronic, manageable disease. ${ }^{1}$

There are now only small efficacy differences between available treatments. As a result, the choice of treatment is based mainly on the side-effect profile of the ARV, drug interactions, resistance barriers, the pharmaceutical form and patient preference. The current approach to the treatment of HIV now allows the patient an increasingly important role in the choice of treatment, with the aim of ensuring maximum adherence. ${ }^{2}$ 
To ensure optimum efficacy at the beginning of treatment, $95 \%-100 \%$ adherence is necessary, but despite this, various studies show that adherence remains inadequate..$^{3-6}$

The majority of existing studies to understand patient preferences for HIV treatment have focused on factors affecting treatment adherence, because patient satisfaction with HIV care and treatment can have a direct impact on adherence. ${ }^{7}$ Factors related to adherence can be broadly divided into three groups, namely treatment-related factors (usually attributes of the medication), social factors (relating to patient characteristics or environment) and disease characteristics (eg, CD4 cell count). ${ }^{7}$ A number of studies have explored adherence factors linked to treatment. ${ }^{8-10}$ In particular a European study identified five treatment attributes influencing patient adherence, namely administration frequency, daily pill burden, number of pills per dose, side effects and effectiveness. ${ }^{11}$ Side effects and effectiveness were found to be most important to PLWH across all five countries. ${ }^{11}$ A recent systematic literature review found that patients who experienced asthenia, confusion, taste disturbances or nausea were less likely to adhere to treatment compared to those who did not experience any side effects. ${ }^{12}$ Perceived effectiveness is another important factor in patient satisfaction and adherence to medication. ${ }^{13}$ In addition, frequency of treatment administration is also a key predictor of patient adherence. ${ }^{14}$ Patient preference and adherence are improved with simple dosing regimens, particularly once-daily dosing; crucially this factor can often determine the difference between success and failure of an ARV regimen. ${ }^{15-18}$

Other studies have shown that factors related to patient characteristics and social support also play a role in patient adherence to HIV medication. ${ }^{7,19-22}$ The characteristics of HIV infection, the emotional impact of HIV, the quality of the patient/doctor relationship and the patient's knowledge about the treatment can also influence their satisfaction and adherence. ${ }^{23-28}$

Although many studies have focused on one or more of these treatment factors, only one study was identified which compared the relative importance of these different factors or the relationships between them at the time we started our study. This US preference study asked 35 PLWH to make trade-offs between various treatment attributes including treatment efficacy, resistance, side effects and convenience. The risk of developing resistance, regimen convenience and the risk of sleep disturbance had the greatest impact on patient treatment preferences. Other side effects most likely to influence patient satisfaction included cholesterol elevation, nausea and diarrhea. ${ }^{29}$

Given the multiplicity of factors influencing adherence to and satisfaction with ARV treatment, it is becoming more widely acknowledged that treatment must be individually tailored, with the choice of treatment and follow up taking into account those factors considered most important by patients. Better understanding of these mechanisms would enable better matching of treatments to patient expectations. With the development of new ARV therapies, it is also important to determine whether there remain unmet needs in the care and treatment of PLWH.

The objective of this study was to elicit patient preferences regarding the principal characteristics of ARV therapies and to explore satisfaction of PLWH in France with their current ARV therapies. The study was composed of two parts, a quantitative study to estimate the relative strength of preference for different attributes associated with ARV therapies, and a qualitative study designed to assess factors influencing patient satisfaction. In addition, it was anticipated that the qualitative part of the study would aid interpretation of the quantitative part, and provide more detailed understanding of the drivers of patient preferences for treatment.

\section{Patients and methods}

This multicenter, cross-sectional, observational epidemiological study was one of five parallel, identical studies conducted in five European countries (France, Italy, Spain, Germany and the UK). The French study was conducted between April and July 2014 in five hospitals and was overseen by an independent scientific committee with representatives of health care professionals and patient organization. The study was approved by the Nord-Ouest III Ethics Committee, the French Consultative Committee on Data Processing for Healthcare Research and the French National Data Processing and Freedoms Commission.

\section{Patients}

The eligibility criteria were identical for both parts of the study. To be included, patients had to be at least 18 years old, to be a current resident in France, to be taking ARV therapy and to have appropriate verbal and written language skills in French. Patients taking part in a clinical trial, acutely unwell or suffering from cognitive impairment that, in the opinion of the investigator, would interfere with the study requirements were excluded in the study.

Patients were selected consecutively from clinic lists by the investigators at each center. They could participate in one or both studies but there was no obligation to participate in both. The following sociodemographic characteristics were considered during patient recruitment: gender, mode of transmission, country of transmission, type of ARV treatment, duration of $\mathrm{ARV}$ regimen, hepatitis $\mathrm{B}$ and $\mathrm{C}$ coinfection 
status. This recruitment methodology aimed to achieve an epidemiologically representative sample of PLWH. Eligible patients interested in participating completed a written informed consent form with the physician.

\section{Quantitative study}

Patient preferences for attributes (characteristics) of ARV treatment were evaluated using discrete choice experiment (DCE) methodology. ${ }^{30-32} \mathrm{~A}$ DCE survey is designed to understand the strength of patient preference for different treatment characteristics. This method consists of presenting patients with different therapies presented pairwise and patients have to choose one or other of the treatment options.

\section{Construction of the DCE}

The treatment attributes for this study were defined on the basis of a literature review and the opinion of the European advisory board (including a French expert, PLWH and health care professionals). The levels of these attributes were identified through existing clinical information, input from clinicians (to determine relevance and thresholds for clinical characteristics such as the risk of side effects), and input from a DCE design expert (to ensure optimal design of the survey during construction). The aim of the attribute and level development was to include treatment attributes that are clinically specific, relevant and comprehensible to PLWH.

The list of eleven attributes proposed by the advisory board underwent a pilot test in one-on-one interviews with five
PLWH. During these interviews, patients were asked to discuss each attribute in detail to determine its relevance to treatment satisfaction and provide feedback on the language used in the attribute levels. Patients were also asked to rank the attributes in terms of importance and to explain their ranking. This exercise proved important in both revising the wording of the attributes and reducing the final number of attributes from eleven to seven. These seven attributes and levels (three levels for each attribute) were then included in the DCE survey (Table 1).

The levels of attributes were then combined into choice sets. The total number of possibilities is obtained by combining the number of attributes with the number of levels determined for each attribute, so for this study $3^{7}=2,187$ scenarios. To minimize the number of possible choice sets (to minimize patient burden), also to obtain a maximum level of information, an orthogonal array was used to select 18 scenarios, with an additional repeated choice set to test participant comprehension of the task (consistency check). The final survey consisted of 19 choice sets, each comprising a choice between two treatments (treatment A versus treatment B). The order of choice sets was randomized for each patient in order to avoid potential ordering effects (Table 2 shows an example choice set). Patients were asked to choose which treatment option they would prefer.

\section{Sample size for the DCE survey}

For DCE studies, conventional calculations of sample size are inappropriate and no formal recommendations exist

Table I Discrete choice experiment - attributes and levels

\begin{tabular}{|c|c|}
\hline Attributes & Levels \\
\hline \multirow[t]{3}{*}{ Viral load reduction } & An undetectable viral load ( $<50$ copies $/ \mathrm{mL}$ ) within 4 weeks remaining undetectable after 3 months \\
\hline & A viral load around 400 copies $/ \mathrm{mL}$ within 4 weeks and undetectable after 3 months \\
\hline & A viral load around I,000 copies $/ \mathrm{mL}$ within 4 weeks and undetectable after 3 months \\
\hline \multirow[t]{3}{*}{ CD4 cell count increase } & An increase of CD4 $+100 / \mathrm{mm}^{3}$ after 3 months of treatment \\
\hline & An increase of CD4 $+50 / \mathrm{mm}^{3}$ after 3 months of treatment \\
\hline & An increase of CD4 $+25 / \mathrm{mm}^{3}$ after 3 months of treatment \\
\hline \multirow[t]{3}{*}{ Side-effects: diarrhea } & You do not experience loose stools as a result of your treatment \\
\hline & You experience 3 episodes of loose stools per day as a result of your treatment \\
\hline & You experience more than 6 episodes of loose stools per day as a result of your treatment \\
\hline Long-term health problems (bone, & No increased risk of developing future health problems \\
\hline \multirow[t]{2}{*}{ kidney disease or heart disease) } & I in 10 people ( $10 \%)$ will experience future health problems \\
\hline & I in 5 people (20\%) will experience future health problems \\
\hline \multirow[t]{3}{*}{ Treatment failure } & All treatment options are available to you \\
\hline & Some antiretroviral treatments are only partially effective \\
\hline & Some antiretroviral treatments cannot be used, while others are only partially effective \\
\hline \multirow[t]{3}{*}{ Food restrictions } & No specific food requirements \\
\hline & All pills must be taken with food \\
\hline & All pills must be taken on an empty stomach \\
\hline \multirow[t]{3}{*}{ Drug-drug interaction } & No drug interactions occur \\
\hline & $\begin{array}{l}\text { You can take other medication but your dose of HIV treatment will be adjusted and this may lead } \\
\text { to a greater chance of side effects }\end{array}$ \\
\hline & You cannot take certain medications \\
\hline
\end{tabular}

Abbreviation: HIV, human immunodeficiency virus. 
Table 2 Discrete choice experiment - example of a choice set

\begin{tabular}{|c|c|c|}
\hline Choice 12 & Treatment A & Treatment B \\
\hline Viral load reduction & $\begin{array}{l}\text { A viral load around I,000 copies } / \mathrm{mL} \text { within } 4 \\
\text { weeks and undetectable after } 3 \text { months }\end{array}$ & $\begin{array}{l}\text { An undetectable viral load }(<50 \text { copies } / \mathrm{mL}) \\
\text { within } 4 \text { weeks remaining undetectable after } \\
3 \text { months }\end{array}$ \\
\hline CD4 cell count increase & $\begin{array}{l}\text { An increase of } C D 4+100 / \mathrm{mm}^{3} \text { after } 3 \text { months } \\
\text { of treatment }\end{array}$ & $\begin{array}{l}\text { An increase of } \mathrm{CD} 4+50 / \mathrm{mm}^{3} \text { after } 3 \text { months } \\
\text { of treatment }\end{array}$ \\
\hline Diarrhea & $\begin{array}{l}\text { You experience more than } 6 \text { episodes of loose } \\
\text { stools per day as a result of your treatment }\end{array}$ & $\begin{array}{l}\text { You do not experience loose stools as a } \\
\text { result of your treatment }\end{array}$ \\
\hline $\begin{array}{l}\text { Long-term health problems (bone, } \\
\text { kidney disease or heart disease) }\end{array}$ & $\begin{array}{l}\text { I in } 10 \text { people }(10 \%) \text { will experience future health } \\
\text { problems }\end{array}$ & $\begin{array}{l}\text { I in } 5 \text { people }(20 \%) \text { will experience future } \\
\text { health problems }\end{array}$ \\
\hline Treatment failure & $\begin{array}{l}\text { Some antiretroviral treatments are only partially } \\
\text { effective }\end{array}$ & $\begin{array}{l}\text { Some antiretroviral treatments cannot be } \\
\text { used, while others are only partially effective }\end{array}$ \\
\hline Food restrictions & No specific food requirements & All pills must be taken with food \\
\hline Drug-drug interaction & $\begin{array}{l}\text { You can take other medication but your dose of } \\
\text { HIV treatment will be adjusted and this may lead } \\
\text { to a greater chance of side effects }\end{array}$ & You cannot take certain medications \\
\hline Which treatment do you prefer? & $\square$ & $\square$ \\
\hline
\end{tabular}

Abbreviation: HIV, human immunodeficiency virus.

regarding the number of subjects to be included. However, Pearmain et al suggested a minimum sample size of 100 individuals to elicit patient preference..$^{33}$

\section{Analysis of the DCE}

A descriptive analysis of the demographic data was conducted. Statistical analysis of the data was carried out using a mixed logit regression model to evaluate patient preference for each treatment attribute. The strength of patient preference for each attribute is determined by the odds ratio (OR) and its 95\% confidence interval (CI), which indicates the odds of preferring a level of an attribute compared to a reference level of the same attribute (all other things being equal). The reference levels chosen for each attribute are the "most preferred" levels. The significance of a specific attribute level refers to whether it has an association with patient preference. Thus, as the adjusted OR moves below 1 , there is less chance of choosing a treatment with this level, compared to the reference level.

\section{Qualitative study}

The qualitative phase of the study involved an in-depth semistructured telephone interview of PLWHs. It was conducted in order to help interpretation of the DCE results, in addition to exploring other factors that influence satisfaction and adherence.

\section{Development of the interview guide}

Three distinct groups of factors having a significant influence on treatment satisfaction for PLWH were identified through a focused literature review (medication-related factors, patient-related factors and physician-related factors) and were included as questions in the patient interview guide. ${ }^{8,28}$
Questions exploring relationships between the different factors were also included, as well as how these factors influenced satisfaction and adherence to treatment.

The European version of the interview guide was finalized after a pilot focus group carried out with five PLWH to confirm the acceptability and wording, and then translated into French using a full forward-back-translation process.

\section{Participant interviews}

Patients were interviewed by an experienced qualitative researcher and all interviews were audio-recorded. Patients were compensated for the time spent with a $€ 30$ gift token.

Based on the previous similar qualitative work, this study aimed to recruit a sample size of 30 patients. Final sample size was determined using the concept of data saturation: the point at which no new information is obtained from additional qualitative data. ${ }^{34,35}$

\section{Data analysis}

A descriptive analysis of the demographic data was carried out. The systematic thematic analysis of the transcripts was assisted by qualitative analysis software (MAXQDA 10). This approach involved two analysts interpreting the transcripts for emerging themes and coding them accordingly. All themes and associated subthemes that arose from the data were recorded in a saturation table. ${ }^{36-38}$ Recruitment was considered complete at the point at which no new information was obtained from additional qualitative data.

\section{Results}

\section{Characteristics of the study sample}

The DCE survey was completed by 101 patients (enrolled by 14 physicians). Most of the patients were male ( $76 \%$ ), with a mean 
age of 46. Patients had been diagnosed with HIV for a mean of 12 years, and $96 \%$ had an undetectable viral load. The sample contained a variety of educational levels, with 8 patients having no formal qualification or diploma (8\%), 21 patients having national vocational qualification level 1, 2 (21\%), 21 patients having high-school diplomas (21\%), 21 patients having short higher education (21\%) and 18 patients having long higher education (18\%). Nine patients had another educational level $(9 \%)$ and three patients preferred not to answer (3\%).

Thirty-one patients were interviewed for the qualitative part (enrolled by ten physicians). No new themes were introduced in the final ten interviews (considered to have reached data saturation). This suggests that the sample size is adequate and additional interviews would have been unlikely to introduce additional concepts. Most of the patients were male (77\%), with a mean age of 50 . Patients had been diagnosed with HIV for a mean of 15 years, and 94\% had an undetectable viral load. Twenty-one patients participated in both studies. Patient characteristics are presented in Table 3.

\section{Analysis of the quantitative study (DCE)}

Of the 101 patients enrolled, three did not meet the consistency check and were excluded from the DCE analysis. Figure 1 presents ORs and their CIs for each of the seven attributes. Most of these attributes were significant predictors of patient choice. Patients had lower preference for a treatment that resulted in higher viral load of 1,000 copies $/ \mathrm{mL}$ after 4 weeks of treatment compared to 50 copies $/ \mathrm{mL}$ (OR: 0.819; CI: 0.674-0.995; $P=0.044)$. This is expected, because higher viral load implies high disease activity, which is not preferred. However, relatively small increases in CD4 count of $+50 / \mathrm{mm}^{3}$ or $+25 / \mathrm{mm}^{3}$ (compared to $+100 / \mathrm{mm}^{3}$ ) was not a statistically significant predictor of patient preference.

Patients placed significant value on the avoidance of side effects, especially diarrhea. Compared with a treatment that does not cause loose stools, patients were $69 \%$ less likely to prefer a treatment associated with frequent diarrhea (six loose stools a day) (OR: 0.309; CI: 0.238-0.402; $P<0.001$ ) and also strongly preferred to avoid treatments with three episodes of loose stools per day (OR: 0.685; CI: 0.569-0.824; $P<0.001)$. This shows the importance given to this adverse effect.

Patients also showed their preference for avoiding some of the longer term toxicities, such as cardiovascular disease and kidney disease. Compared with a treatment without increased risk, patients were $47 \%$ less likely to choose a treatment associated with a $10 \%$ long-term risk of such problems (OR: 0.534; CI: 0.442-0.645; $P<0.001$ ). Patients were 77\% less likely to choose a treatment with a $20 \%$ long-term risk (OR: 0.229; CI: 0.178-0.294; $P<0.001$ ).
Table 3 Patient characteristics

\begin{tabular}{|c|c|c|c|c|}
\hline & \multicolumn{2}{|c|}{$\begin{array}{l}\text { Qualitative } \\
\text { data, } \mathbf{n}=\mathbf{3} \mathbf{I}^{\mathrm{a}}\end{array}$} & \multicolumn{2}{|c|}{$\begin{array}{l}\text { Quantitative } \\
\text { data, } n=|0|^{b}\end{array}$} \\
\hline \multicolumn{5}{|l|}{ Age (years) } \\
\hline Mean (SD) & \multicolumn{2}{|l|}{$49.7(13.4)$} & \multicolumn{2}{|c|}{$46.0(10.0)$} \\
\hline Range & \multicolumn{2}{|l|}{$27-78$} & \multicolumn{2}{|l|}{$25-74$} \\
\hline Missing data & \multicolumn{2}{|l|}{0} & \multicolumn{2}{|l|}{0} \\
\hline \multicolumn{5}{|l|}{ Gender } \\
\hline Male/female & $\begin{array}{l}24 \\
(77.4 \%)\end{array}$ & $\begin{array}{l}7 \\
(22.6 \%)\end{array}$ & $\begin{array}{l}77 \\
(76.2 \%)\end{array}$ & $\begin{array}{l}24 \\
(23.8 \%)\end{array}$ \\
\hline Missing data & \multicolumn{2}{|l|}{0} & \multicolumn{2}{|l|}{0} \\
\hline \multicolumn{5}{|c|}{ Years since diagnosis } \\
\hline Mean (SD) & \multicolumn{2}{|l|}{$14.5(8.7)$} & \multicolumn{2}{|l|}{ I $2.0(8.0)$} \\
\hline Range & \multicolumn{2}{|l|}{$2-30$} & \multicolumn{2}{|l|}{$0-31$} \\
\hline Missing data & \multicolumn{2}{|l|}{1} & \multicolumn{2}{|l|}{0} \\
\hline \multicolumn{5}{|l|}{ Current viral load } \\
\hline $\begin{array}{l}\text { Nondetectable/ } \\
\text { detectable }\end{array}$ & $\begin{array}{l}29 \\
(93.5 \%)\end{array}$ & $\begin{array}{l}2 \\
(6.5 \%)\end{array}$ & $\begin{array}{l}97 \\
(96.0 \%)\end{array}$ & $\begin{array}{l}4 \\
(4.0 \%)\end{array}$ \\
\hline Missing data & \multicolumn{2}{|l|}{0} & \multicolumn{2}{|l|}{0} \\
\hline \multicolumn{5}{|c|}{ Most recent CD4 count $\left(/ \mathrm{mm}^{3}\right)$} \\
\hline$<200$ & \multicolumn{2}{|l|}{$0(0.0 \%)$} & \multicolumn{2}{|l|}{$5(4.9 \%)$} \\
\hline $200-400$ & \multicolumn{2}{|l|}{$5(16.1 \%)$} & \multicolumn{2}{|c|}{$13(12.9 \%)$} \\
\hline$\geq 400$ & $26(83.9 \%)$ & & $69(68.3 \%$ & \\
\hline Not sure & 0 & & $14(13.9 \%$ & \\
\hline Missing data & 0 & & 0 & \\
\hline Number of years & HIV medic & tion (yea & & \\
\hline$\geq 10$ & $17(56.7 \%)$ & & $46(45.5 \%$ & \\
\hline $4->10$ & $10(33.3 \%)$ & & $30(29.7 \%$ & \\
\hline $\mathrm{I}-3$ & $3(10.0 \%)$ & & $19(18.9 \%$ & \\
\hline$<1$ & $0(0.0 \%)$ & & $6(5.9 \%)$ & \\
\hline Missing data & 1 & & 0 & \\
\hline Number of times & itched med & cation & & \\
\hline 3 or more times & $16(53.4 \%)$ & & $41(41.0 \%$ & \\
\hline Twice & 4 (I3.3\%) & & $16(16.0 \%$ & \\
\hline Once & $6(20.0 \%)$ & & $22(22.0 \%$ & \\
\hline Never & $4(13.3 \%)$ & & $21(21.0 \%$ & \\
\hline Missing data & $\mathrm{I}$ & & 1 & \\
\hline Current ARV the & & & & \\
\hline NNRTI & $14(45.2 \%)$ & & $49(48.5 \%$ & \\
\hline Protease inhibitors & II (35.5\%) & & $34(33.7 \%$ & \\
\hline Integrase inhibitors & $5(16.1 \%)$ & & $18(17.8 \%$ & \\
\hline CCR5 inhibitors & $0(0.0 \%)$ & & $4(4.0 \%)$ & \\
\hline Missing data & 2 & & 5 & \\
\hline
\end{tabular}

Notes: a Data completed by the investigators. 'Data completed by the patients. 'Some combinations contain more than two-third agents.

Abbreviations: ARV, antiretroviral drugs; HIV, human immunodeficiency virus; SD, standard deviation.

Patients indicated that it was important for them to avoid treatment failure which would affect the efficacy of other ARVs (OR: 0.659; CI: 0.543-0.800; $P<0.001$ ). Patients strongly preferred avoiding treatment failure if it meant 


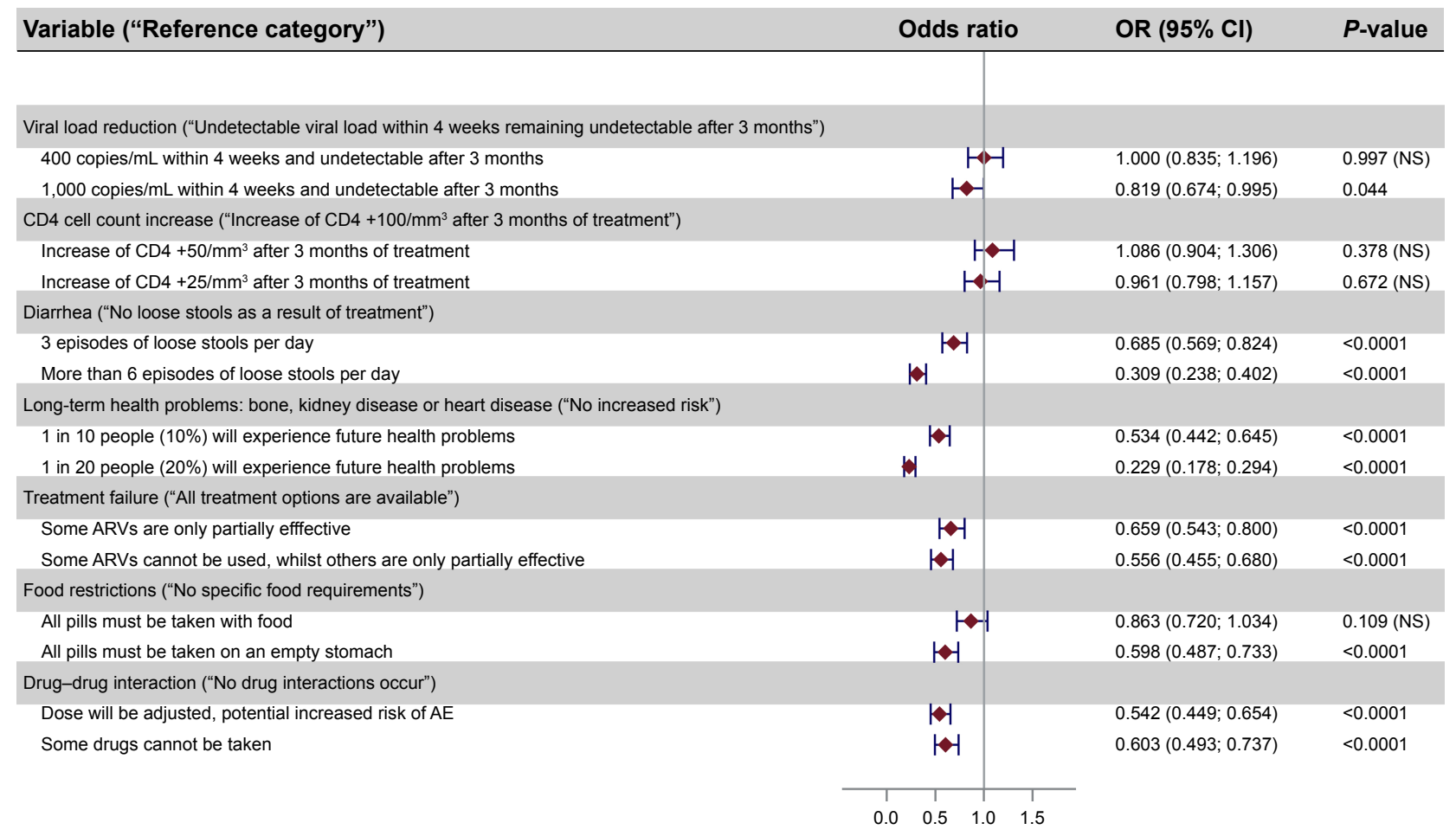

Figure I Discrete choice experiment results.

Abbreviations: ARV, antiretroviral drug; $\mathrm{Cl}$, confidence intervals; NS, not significant.

that other drugs could not be used at all (OR: 0.556; CI: $0.455-0.680 ; P<0.001)$.

Patients were concerned about the potential risk of drugdrug interactions (DDI), mostly about treatments where a potential DDI would lead to a dose adjustment and increased risk of side effects (OR: 0.542; CI: 0.449-0.654; $P<0.001$ ). The use of ARVs which precluded the use of other drugs because of DDI was also an important concern (OR: 0.603; CI: $0.493-0.737 ; P<0.001)$.

Patients were less concerned about food constraints. Treatments with no restrictions around food intake were not significantly preferred to those that needed to be taken with food. Patients significantly preferred to avoid treatments that needed to be taken on an empty stomach (OR: 0.598; CI: $0.487-0.733 ; P<0.001)$.

\section{Analysis of the qualitative study Treatment attributes}

The majority of patients equated an effective treatment with a reduction in their viral load and an increase in their CD4 cell count. Some also reported that they knew their treatment to be effective because they achieved or maintained an undetectable viral load.

Patients commonly reported having experienced diarrhea as a result of their current medication. For some, this only occurred at the beginning of their treatment and had reduced or disappeared as they had adjusted to their medication but a few patients spoke about an impact on their social life. Despite having experienced some sort of side effect either from previous or current medication, the majority of patients were satisfied with their current treatment in terms of efficacy and convenience and they reported not being worried or concerned about these side effects.

Nearly all patients reported that they were aware of the potential long-term health problems associated with ARV therapies, including risk of cardiovascular disease, osteoporosis, raised cholesterol, liver damage and kidney damage. Most patients expressed some level of concern about these potential long-term effects and a few reported that they had already experienced some of these.

Several patients reported finding the restrictions on when to take their medication more inconvenient or difficult to adhere to if they were not feeling hungry when they were supposed to take it, or if they were away from home in a location where other people may see them taking their medication.

Regarding DDI, patients reported feeling that they had been well informed about the risks involved with drug interactions and had discussed these with their doctor. Patients generally felt that they trusted their doctor to prescribe medications that are safe to take in combination, and 
were comfortable discussing these issues with their doctor, if necessary.

\section{Concept elicitation}

Broader concepts were also covered during the interviews. A wide range of themes emerged from the qualitative study and were categorized into 16 themes and 112 subthemes. The conceptual model demonstrates how these multiple themes influence treatment satisfaction and medication adherence.

\section{Patient satisfaction with ARV therapy}

Satisfaction regarding medication characteristics is described through patient quotes in Table 4. Interviewed patients were mostly satisfied with the packaging, color, shape and size of tablets, as well as their texture, taste and smell (quotes a-f).

Most participants reported no impact on body image due to ARV therapy. The few participants who reported changes spoke of gaining weight and experiencing lipodystrophy.

Table 4 Qualitative study - patient quotes

\section{Patient satisfaction with ARV therapy}

a "The colors help me to take the right tablets"

"It goes down easily. There is neither taste nor texture, in fact, I just swallow it and that is it"

"Others in the past were not so easy, I had to get some bread afterwards"

"No, they do not have any taste. They are easy to swallow"

b 'Yes, frankly I don't think it's a good idea to show the boxes (on TV) because if in your family you have someone with the medication, they can find out and suspect and that's not good. It could be improved, really, instead of looking like 'HIV boxes"'

c "But the problem is worry about the color of (ARV name) which is blue and if you are around in public with people who are taking pills, these are all white, so they know what you are taking"

d "Sometimes I feel it does not go down, it remains in the throat"

"It bothered me at first. Anyway, this is the treatment to survive, we must make our choice"

e "Yes, but it's also the shape. It is big; if they made them rounder, so they were easier to take"

$\mathrm{f} \quad$ "When you see the number of tablets it was before, I find it (current treatment) great. I take fewer tablets than people who have diabetes or other chronic diseases"

"No, I prefer to take them all at once. That is much easier. And it is good to take these in the morning because I can go wandering after. It is always annoying if I have to take them with me all day"

g (Did it modify your body image?) "No. Well, I take care of myself a little more"

$\mathrm{h} \quad$ (Did it modify your body image?) "It's the weak link really. Having gained $9 \mathrm{~kg}$ is a bit difficult for me, in terms of self-esteem. I feel less confident. Of course beauty is subjective"

\section{Factors affecting adherence}

i "She gives me the information every time I see her, and the last time I saw her she showed me the graph of the evolution, and it was really interesting because seeing the results each time is good but seeing the evolution is even more important, because there was a decrease over the year, and the viral load decreasing and then becoming undetectable for the last 3 years. It is visual, and pushes you to take your treatment correctly"

"The doctor gives me information on my viral load, CD4, etc. all the time. For a month I forgot to take my morning tablet and I went from undetectable viral load to detectable viral load. It is very quick"

"I do not want to miss any dose actually. It has become part of my habits. That would affect the undetectable viral load, so I am being very careful with that"

j "The fact that the medication blocks the infectious process, yes of course it makes you take it every day. Regularly"

k (Do worries about sexual transmission make you more eager to take your medication?)

"Yes, it definitely incites me to take them"

I "I really comply to avoid resistance, knowing that I was diagnosed with billions of viruses in my bloodstream. I was weeks from developing the full blown disease. So I am very careful about resistance"

"I am worried that one day the treatment will stop working. That's why I am very compliant"

m "I have heard about that. After a while, we should change medication. Frankly, I do not think about it that much. As long as there are followups and if at any time it does not work, the doctors will see that and change the treatment"

n "I would like to take all the tablets in the evening and stop the morning one. In the evening I always take my treatment but I very often forget to take my tablet in the morning. So they will change the dosage so that I take the treatment only once a day"

"I was on a boat trip in (place name) and it was difficult to think about that (taking medication) when you were on the boat"

"Not forgot, but I was invited to a barbeque and there was a bit of alcohol, so I did not take my dose and I think it influenced the results a bit" "Yes, it is more complicated during the trip because I am not home. I do not have to hide but I just have to be more discreet, especially when the person does not know about my health condition"

P (So not taking the medication regularly is not linked to a lack of confidence in your medication) "No. I think it's more complex than that. It's a way to deny what exists. It's unconscious. At the moment I force myself to take it every day, but sometimes I slip"

q "I thought about it, looked at the pros and cons, but the side effects that I encountered - I am not saying it's the case for everyone - were insignificant compared to the benefits of taking the treatment regularly"

Abbreviations: ARV, antiretroviral drugs; HIV, human immunodeficiency virus. 
They talked about impact on their self-esteem, confidence and mood overall. Participants did not always perceive that their weight gain or excess cellulite was due to medication. Some participants reported that medication had a positive impact on their lifestyle and body image by taking exercise and eating healthily (quotes $g$ and $h$ ).

\section{Factors affecting adherence to ARVs}

Although many factors were associated with adherence to ARVs, most of the patients said they took their treatment in accordance with the prescription.

Having information and feedback about their viral load and cell count at each medical visit helps patients to understand the importance of taking their treatment on a regular basis and had a positive influence on their adherence (Table 4, i). Patients who reported having confidence in the efficacy of treatments also explained the positive impact that understanding the medication can have on adherence (Table $4, j$ ). A relationship of trust between the patient and the doctor is also one of the factors that positively influence adherence, particularly by means of patient information, and the quality of discussions about side effects and long-term effects of treatments.

The fear of sexual transmission to their partners also improved adherence to ARVs (Table 4, k). Some patients were worried about the possibility of treatment failure or the development of treatment resistance and, as a result, were aware of the importance of taking their medication regularly (Table 4, 1). Other patients felt less concerned about resistance because they take their medication as prescribed and continue to have good test results (Table 4, m). A few

Table 5 Factors affecting ARVs adherence

ARV adherence facilitators
Treatment effectiveness
Information and feedback about viral load and cell count
Fear of sexual transmission to partners
Possible development of treatment resistance (worry about treatment
failure)
Simplification of ARV regimens
Trusting relationship between patients and clinicians
ARVs adherence barriers
Modifications of the daily routine (eg, holidays, lunch with friends)
Patient's unconscious desire to avoid thinking about the disease
Food restrictions
Factors with no impact on ARVs adherence
Long-term health problems (no alternative yet)
Short-term side effects
Drug interactions (trust in the clinician to choose the best possible
option)

Abbreviation: ARV, antiretroviral drugs. participants mentioned other factors which affected their adherence, including the complexity of the dosing regimen for ARVs (Table 4, n).

Conversely, other factors were identified as having a negative impact on adherence. These included the social life of PLWH (Table 4, o) and the patient's unconscious desire to avoid thinking about the disease (Table 4, p). Finally, experiencing side effects (such as diarrhea, fatigue or nausea and lipodystrophy) did not impair treatment adherence (Table 4, q). Factors affecting adherence are synthetized in Table 5.

\section{Discussion}

This study provides new insights into the importance that PLWH place on certain attributes of ARV therapy. The relationship between treatment satisfaction and certain characteristics of ARVs has been evaluated previously in a small number of qualitative studies. Quantitative approaches such as DCE, in which patients are asked to choose between treatments attributes and make trade-offs, provide additional information since they allow the relative importance of these attributes to be compared. Nonetheless, direct qualitative assessment allows more exhaustive coverage of the aspects of ARV treatment that are important to patients. For this reason, it is of interest to combine quantitative (DCE) and qualitative approaches in the same study.

In the quantitative study, the DCE attributes of the treatment can be categorized into those relating to quality of life (diarrhea, long-term health problems), those relating to taking the treatment (DDI and food restrictions) and those relating to the efficacy of the treatment (viral load, CD4 cell count and treatment failure). The ORs showed that patient placed most importance on attributes which can have an impact on quality of life and taking treatment, rather than those affecting efficacy. One possible explanation for this could be that the study sample included patients experienced with ARTs whose infection was well controlled. For this reason, they may be aware that their treatment is effective and may take this for granted when making treatment choices. Furthermore, the DCE results also underline that treatments with a risk of DDI are a concern when choosing ARVs. Although this appeared to be a constraint only for the doctor, it is also a concern for the patient, and may increase with the patients' age and associated comorbidities. ${ }^{39,40}$ This study is the first one carried out using discrete choice methods relating to satisfaction of PLWH treated with ARVs in France. A recently published study exploring 131 physicians' views of patient treatment preferences in Germany found that avoiding treatments that 
caused visible signs of disease, avoiding diarrhea and nausea, and empowering patients to self-administer treatment, were attributes that had the biggest impact on patient preference for treatment. ${ }^{41}$ The attributes evaluated in this study were different from those in ours but, in both studies, attributes related to quality of life emerged as key factors.

Analysis of the qualitative data on treatment attributes provided support for the findings of the DCE, highlighting the importance patients place on treatment efficacy and demonstrating the importance of other characteristics, such as concerns about potential long-term impact of treatments. In a trade-off, patients will choose a treatment with as few side effects and long-term health problems as possible, and as low a risk of treatment failure and DDI as possible. Moreover, when interviewed separately on each attribute, and based on their current treatment, they conceded that certain negative attributes, such as side effects, were acceptable, because they were otherwise satisfied with their current treatment in terms of efficacy and convenience. Patients were aware of the risk of treatment failure and DDI, but they trusted their doctor's prescription.

Many factors influencing treatment satisfaction were revealed through the qualitative analysis, including pill size, effectiveness of medication, worry about sexual transmission and impact on social life. Opportunities for improving treatments to increase patient satisfaction and adherence were also highlighted, notably less visible packaging to limit stigmatization, smaller and more discreet tablets, greater flexibility in taking doses and fewer food restrictions.

The qualitative analysis indicated that certain treatment attributes may influence adherence. For example, for many patients, having a good understanding of the expected benefits and risks of their treatment had a positive impact on their adherence. This is consistent with previous studies, which have found that adherence was influenced by how effective patients perceived their medication to be. For example, a large European study showed effectiveness to be one of the most important determinants of adherence..$^{11,13}$ Many patients discussed the importance of receiving feedback from their clinician about viral load and CD4 cell count and some patients said the trust they had in their clinician gave them confidence in the effectiveness of their treatment. To encourage adherence, it is, therefore, important to develop tools to monitor changes in the biological efficacy of treatment. This need is reflected in current approaches to therapeutic education in France. This finding is also consistent with those of previous studies demonstrating the important role that clinicians play in treatment satisfaction and adherence, and underlines the importance of the quality of clinician-patient dialogue in optimizing patient satisfaction and adherence to treatment. ${ }^{24,26}$

Regarding the external validity of the overall study, patients from both parts of the study had similar characteristics and sampling provided a representative group of patients regularly seen in medical consultation. ${ }^{42}$ The majority of patients in this study had been taking ARV treatments for a number of years and had switched treatments at least twice, so were highly experienced in treatment for HIV. Nonetheless, given the relatively small size of the sample, it was difficult to stratify the patient sample to cover the anticipated spread of sociodemographic characteristics of PLWH in order to obtain a representative sample. For this reason, the advisory board proposed that sampling patients consecutively from a clinic list would be more appropriate, in order to avoid physicians targeting patients from particular demographic groups that would be more engaged with the process.

Certain patients were included in both studies to facilitate patient recruitment. However, the risk that patients' responses may be biased due to participation in both studies was considered to be limited.

Certain limitations associated with the DCE methodology should be considered. This powerful multidimensional tool is used to analyze simultaneously the influence of multiple attributes, the ORs providing information about the relative importance of each attribute. However, the performed analysis does not allow comparison of the ORs between the different attributes. It is also difficult to compare the importance of different attributes, expressed in different units. For example, the viral load is expressed as copies $/ \mathrm{mL}$, whereas other attributes are presented as probabilities or categorical variables. Finally, although the chosen attributes and their levels had been selected from a literature review and from discussion with clinicians and expert patients, it is possible that other characteristics of treatments influencing patient preferences were not evaluated. One of the main limitations of the qualitative part of the study is that the trends and themes developed are only representative of those patients in the study sample and may not be generalized to represent the views of PLWH across the whole country.

\section{Conclusion}

This study provides a new light on preferences of PLWHs regarding different attributes associated with ARV therapies and on the main factors associated with PLWH 
satisfaction. One of the key results is the importance placed by PLWHs on characteristics of ARVs related to quality of life, in particular for ARV therapy with no increased risk of long-term health problems and side-effects. This should be taken into consideration when prescribing ARV therapies, in order to optimize adherence and satisfaction of PLWHs.

These data will be compared to those from the four other participating European countries in order to identify similarities and differences in the factors influencing patient satisfaction and preferences between countries.

\section{Acknowledgments}

We would like to thank the patients who agreed to take part in this study, the investigators, Miranda Murray, Nathalie Dang (ViiV Healthcare, London, UK), Paul Swinburn, Katy Gallop, Hayley de Freitas, Andrew Lloyd (Icon plc, Oxford, UK), Julie Salia (patient reported outcomes, Lyon), Céline Aubin and Camille Correia Da Silva (GlaxoSmithKline, Paris, France). Study sponsored and financed by ViiV Healthcare.

\section{Author contributions}

S Brégigeon-Ronot, A Cheret, A Cabié, T Prazuck and JJ Parienti approved the protocol, recruited patients and reviewed the analyses. A Volny-Anne approved the protocol and reviewed the analyses. S Ali performed the data analysis. C Bottomley contributed to writing the article, monitoring and performing the data analysis. L Finkielsztejn approved the protocol, reviewed the analyses and was involved in monitoring. C Philippe was responsible for recruitment and monitoring of centers, gathering data, monitoring, reviewing the analyses and writing the article. All authors read and approved the final version of the manuscript and approved its submission. JJ Parienti was responsible for submission of the manuscript. All authors contributed toward data analysis, drafting and revising the paper and agree to be accountable for all aspects of the work.

\section{Disclosure}

S Brégigeon-Ronot: Gilead, Janssen, ViiV Healthcare. A Cheret: ViiV Healthcare. A Cabié: Gilead, Janssen, ViiV Healthcare. T Prazuck: Gilead, ViiV Healthcare, Janssen. A Volny-Anne: none. S Ali: employed by Icon, contract research organization at time of study. C Bottomley: employed by Icon, contract research organization at time of study. L Finkielsztejn: employed by ViiV Healthcare. C Philippe: employed by Qualees, contract research organization. JJ Parienti: Gilead science, Janssen Pharmaceuticals, ViiV
Healthcare, MSD. The authors report no other conflicts of interest in this work.

\section{References}

1. Panel on Antiretroviral Guidelines for Adults and Adolescents. Guidelines for the use of antiretroviral agents in HIV-1-infected adults and adolescents. Department of Health and Human Services. Available from: http://www.aidsinfo.nih.gov/ContentFiles/AdultandAdolescentGL.pdf. Accessed April 11, 2016.

2. Morlat P. Prise en charge médicale des personnes vivant avec le VIH. Recommandations du groupe d'experts - Rapport 2013. Sous la direction du Pr Philippe Morlat et sous l'égide du CNS et de l'ANRS [Medical care of people living with HIV. Expert group recommendations - 2013 report]. Available from: http://www.sante. gouv.fr/IMG/pdf/Rapport_Morlat_2013_Mise_en_ligne.pdf. Accessed April 11, 2016. French.

3. Delfraissy JF. Prise en charge des personnes infectées par le VIH: Recommandations du groupe d'experts - 2002 [Medical care of people living with HIV. Expert group recommendations - 2002 report]. Available from: http://www.ladocumentationfrancaise.fr/var/storage/ rapports-publics/034000460.pdf. Accessed April 11, 2016. French.

4. Turner BJ. Adherence to antiretroviral therapy by human immunodeficiency virus-infected patients. J Infect Dis. 2002;185(Suppl 2): S143-S151.

5. Ammassari A, Murri R, Pezzotti P, et al. Self-reported symptoms and medication side effects influence adherence to highly active antiretroviral therapy in persons with HIV infection. $J$ Acquir Immune Defic Syndr. 2001;28(5):445-449.

6. Paterson DL, Swindells S, Mohr J, et al. Adherence to protease inhibitor therapy and outcomes in patients with HIV infection. Ann Intern Med. 2000;133(1):21-30.

7. Langebeek N, Gisolf EH, Reiss P, et al. Predictors and correlates of adherence to antiretroviral therapy (ART) for chronic HIV infection: a meta-analysis. BMC Med. 2014;12:142.

8. Beusterien KM, Davis EA, Flood R, Howard K, Jordan J. HIV patient insight on adhering to medication: a qualitative analysis. AIDS Care. 2008;20(2):244-252.

9. Conway B. The role of adherence to antiretroviral therapy in the management of HIV infection. J Acquir Immune Defic Syndr. 2007; 45(Suppl 1):S14-S18.

10. Stone VE, Jordan J, Tolson J, Miller R, Pilon T. Perspectives on adherence and simplicity for HIV-infected patients on antiretroviral therapy: self-report of the relative importance of multiple attributes of highly active antiretroviral therapy (HAART) regimens in predicting adherence. J Acquir Immune Defic Syndr. 2004;36(3):808-816.

11. Moyle G. The assessing patients' preferred treatments (APPT-1) study. Int J STD AIDS. 2003;14(Suppl 1):34-36.

12. Al-Dakkak I, Patel S, McCann E, Gadkari A, Prajapati G, Maiese EM. The impact of specific HIV treatment-related adverse events on adherence to antiretroviral therapy: a systematic review and meta-analysis. AIDS Care. 2013;25(4):400-414.

13. Lamiraud K, Moatti JP, Raffi F, et al. Adherence to and effectiveness of highly active antiretroviral treatment for HIV infection: assessing the bidirectional relationship. Med Care. 2012;50(5):410-418.

14. Cohen CJ, Meyers JL, Davis KL. Association between daily antiretroviral pill burden and treatment adherence, hospitalisation risk, and other healthcare utilisation and costs in a US medicaid population with HIV. BMJ Open. 2013;3(8):e003028.

15. Parienti JJ, Bangsberg DR, Verdon R, Gardner EM. Better adherence with once-daily antiretroviral regimens: a meta-analysis. Clin Infect Dis. 2009;48(4):484-488.

16. DeJesus E, Young B, Morales-Ramirez JO, et al. Simplification of antiretroviral therapy to a single tablet regimen consisting of efavirenz, emtracitabine and tenofavir disoproxil fumarate versus unmodified antiretroviral therapy in a virologically suppressed HIV-1 infected patients. J Acquir Immune Defic Syndr. 2009;51(2):163-174. 
17. Hodder SL, Mounzer K, DeJesus E, et al. Patient-reported outcomes in virologically suppressed, HIV-1 infected subjects after switching to a simplified, single tablet regimen of efavirenz, emtricitabine and tenofovir DF. AIDS Patient Care STDS. 2010;24(2):115-125.

18. Airioldi M, Zaccarelli M, Bisi L, et al. One-pill once-a-day HAART: a simplification strategy that improves adherence and quality of life of HIV-infected subjects. Patient Prefer Adherence. 2010;4:115-125.

19. Cook JA, Grey DD, Burke-Miller JK, et al. Illicit drug use, depression and their association with highly active antiretroviral therapy in HIVpositive women. Drug Alcohol Depend. 2007;89(1):74-81.

20. Fields EL, Bogart LM, Thurston IB, et al. Qualitative comparison of barriers to antiretroviral medication adherence among perinatally and behaviorally HIV-infected youth. In conference: Society for Adolescent Health and Medicine Annual Meeting: Impact of Trauma on Teens: Building the Safety Net 2012 New Orleans, LA United States. 2012. Available from: http://www.iapac.org/AdherenceConference/ presentations/ADH6_69948.ppt. Accessed July 20, 2015.

21. Power R, Koopman C, Volk J, et al. Social support, substance use, and denial in relationship to antiretroviral treatment adherence among HIV-infected persons. AIDS Patient Care STDS. 2003;17(5):245-252.

22. Kelly DJ, Hartman C, Graham J, Kallen MA, Giordiano TP. Social support as a predictor of early diagnosis, linkage, retention and adherence to HIV care: results from The Steps Study. J Assoc Nurses AIDS Care. 2014;25(5):405-413.

23. Catz SL, Kelly JA, Bogart LM, Benotsch EG, McAuliffe TL. Patterns, correlates, and barriers to medication adherence among persons prescribed new treatments for HIV disease. Health Psychol. 2000; 19(2):124-133.

24. Katz IT, Ryu AE, Onuegbu AG, et al. Impact of HIV-related stigma on treatment adherence: systematic review and meta-synthesis. J Int AIDS Soc. 2013;16(3 Suppl 2):18640.

25. Ingersoll KS, Heckman CJ. Patient-clinician relationships and treatment system effects on HIV medication adherence. AIDS Behav. 2005; 9(1):89-101.

26. Flickinger TE, Saha S, Moore RD, Beach MC. Higher quality communication and relationships are associated with improved patient engagement in HIV care. J Acquir Immune Defic Syndr. 2013;63(3): 362-366.

27. Kalichman SC, Pope H, White D, et al. Association between health literacy and HIV treatment adherence: further evidence from objectively measured medication adherence. J Int Assoc Physicians AIDS Care. 2008;7(6):317-323.

28. Kremer H, Ironson G, Porr M. Spiritual and mind-body beliefs as barriers and motivators to HIV-treatment decision-making and medication adherence? A qualitative study. AIDS Patient Care STDS. 2009;23(2):127-134

29. Beusterien KM, Dziekan K, Flood E, Harding G, Jordan JC. Understanding patient preferences for HIV medications using adaptive conjoint analysis: feasibility assessment. Value Health. 2005;8(4):453-461.
30. Lancsar E, Louviere J. Conducting discrete choice experiments to inform healthcare decision making: a user's guide. Pharmacoeconomics. 2008;26(8):661-677.

31. Reed Johnson F, Lancsar E, Marshall D, et al. Constructing experimental designs for discrete-choice experiments: report of the ISPOR Conjoint Analysis Experimental Design Good Research Practices Task Force. Value Health. 2013;16(1):3-13.

32. Ryan GW, Wagner GJ. Pill taking "routinization": a critical factor to understanding episodic medication adherence. AIDS Care. 2003; 15(6):795-806.

33. Pearmain D, Swanson J, Kroes E, Bradley M. Stated Preference Techniques: A Guide to Practice. 2nd ed. The Hague: Steer Davies Gleave and Hague Consulting Group; 1991.

34. Rothman M, Burke L, Erickson P, Leidy NK, Patrick DL, Petrie CD. Use of existing patient-reported outcome (PRO) instruments and their modification: the ISPOR good research practices for evaluating and documenting content validity for the use of existing instruments and their modification PRO task force report. Value Health. 2009;12(8): 1075-1083.

35. Guidance for Industry. Patient-Reported Outcome Measures: use in medical product development to support labelling claims. 2009. Available from: www.fda.gov/downloads/Drugs/Guidances/UCM193282. pdf. Accessed April 11, 2016.

36. Gibbs G. Analyzing Qualitative Data (Qualitative Research Kit). London, USA: Sage; 2007.

37. Kerr C, Nixon A, Wild D. Assessing and demonstrating data saturation in qualitative inquiry supporting patient-reported outcomes research. Expert Rev Pharmacoecon Outcomes Res. 2010;10(3):269-281.

38. Glaser B, Strauss A. The Discovery of Grounded Theory: Strategies for Qualitative Research. Chicago, IL: Aldine Publishing Company; 1967.

39. Schouten J, Wit FW, Stolte IG, et al. Cross-sectional comparison of the prevalence of age-associated comorbidities and their risk factors between HIV-infected and uninfected individuals: the AGEhIV cohort study. Clin Infect Dis. 2014;59(12):1787-1797.

40. Smit M, Brinkman K, Geerlings S, et al. Future challenges for clinical care of an ageing population infected with HIV: a modelling study. Lancet Infect Dis. 2015;15(7):810-818.

41. Mühlbacher AC, Stoll M, Mahlich J, Nübling M. Patient preferences for HIV/AIDS therapy - a discrete choice experiment. Health Econ Rev. 2013;3(1):14.

42. Dray-Spira RM, Aubrière C, Marcellin F, et al. Health status of people living with HIV followed at hospital in metropolitan France in 2011 and characteristics of those recently diagnosed. Results of the ANRSVESPA2 Study. Bulletin épidémiologique hebdomadaire $\mathrm{n}^{\circ} 26-27$ du 2 juillet 2013, Available from: http://invs.santepubliquefrance.fr// beh/2013/27/2013_26-27_1.html. Accessed July 20, 2015.
Patient Preference and Adherence

\section{Publish your work in this journal}

Patient Preference and Adherence is an international, peer-reviewed, open access journal that focuses on the growing importance of patient preference and adherence throughout the therapeutic continuum. Patient satisfaction, acceptability, quality of life, compliance, persistence and their role in developing new therapeutic modalities and compounds to optimize

\section{Dovepress}

clinical outcomes for existing disease states are major areas of interest for the journal. This journal has been accepted for indexing on PubMed Central. The manuscript management system is completely online and includes a very quick and fair peer-review system, which is all easy to use. Visit http://www. dovepress.com/testimonials.php to read real quotes from published authors. 